FERMIILAB-TM-1745

SSCL-N-765

\title{
SSC 50mm Collider Dipole Cryostat Single Tube Support Post Conceptual Design and Analysis
}

\author{
T. Nicol \\ Fermi National Accelerator Laboratory \\ P.O. Box 500, Batavia, Illinois 60510
}

August 1991 


\section{Disclaimer}

This report was prepared as an account of work sponsored by an agency of the United States Government. Neither the United States Government nor any agency thereof, nor any of their employees, makes any warranty, express or implied, or assumes any legal liability or responsibility for the accuracy, completeness, or usefullness of any information, apparatus, product, or process disclosed, or represents that its use would not infringe privately owned rights. Reference herein to any specific commercial product, process, or service by trade name, trademark, manufacturer, or otherwise, does not necessarily constitute or imply its endorsement, recommendation, or favoring by the United States Government or any agency thereof. The views and opinions of authors expressed herein do not necessarily state or reflect those of the United States Government or any agency thereof. 
TM-1745

SSCL-N-765

\title{
SSC 50mm Collider Dipole Cryostat Single Tube Support Post Conceptual Design and Analysis
}

\author{
Thomas H. Nicol \\ Fermi National Accelerator Laboratory \\ P.O. Box 500 \\ Batavia, IL 60510 \\ July 9, 1991
}

\section{Introduction}

Superconducting Super Collider (SSC) dipole magnet cold masses are connected to the cryostat vacuum vessel at five places equally spaced along their length. Five supports limit sag of the cold assembly due to its own weight to a level consistent with the final magnet alignment specifications. ${ }^{1}$ The supports currently used in the $50 \mathrm{~mm}$ dipoles being built at Fermilab and Brookhaven are adaptations of the design developed during the $40 \mathrm{~mm}$ design program at Fermilab. The design essentially consists of two composite tubes nested within each other as a means of maximizing the thermal path length. In addition it provides an ideal way to utilize materials best suited for the temperature range over which they must operate. Filament wound S-glass is used between $300 \mathrm{~K}$ and $80 \mathrm{~K}$. Filament wound graphite fiber is used between $80 \mathrm{~K}$ and $20 \mathrm{~K}$ and between $20 \mathrm{~K}$ and 4.5K. S-glass is a better thermal performer above approximately $40 \mathrm{~K}$. Graphite composites are ideally suited for operation below $40 \mathrm{~K}$. The designs for both the $40 \mathrm{~mm}$ and $50 \mathrm{~mm}$ reentrant supports are well documented in the literature. ${ }^{2-5}$ Complete coverage is outside the scope of this report. Figure 1 illustrates a cross section through the current design for $50 \mathrm{~mm}$ collider dipoles at one of the five supports. Figure 2 illustrates an isometric cutaway of the support post itself.

The current design of the reentrant support has two major drawbacks. First, it requires very tight dimensional control on all components; composite tubes and metal attachment parts. Second, it is expensive, with cost being driven by both the tolerance constraints and by a complex assembly procedure. It seems clear that production magnets will require a support structure which is considerably less expensive than that which is currently used. The unit cost for support posts for $50 \mathrm{~mm}$ prototype magnets is on the order of $\$ 2500$ in quantities sufficient for 20 magnets (100 supports). 
Work at Brookhaven National Laboratory and the SSC Laboratory over the past two years on RHIC cryostat support structures led to the development of a support post fabricated using Ultem-2100, an injection molded, chopped glass fiber, composite material. ${ }^{6}$ Due to its apparent cost advantage, the injection molding concept has found strong support among industrial contractors working on the design of production collider dipoles and quadrupoles. It may not, however, be the panacea that it is perceived to be for SSC dipoles. Space is limited in collider dipole cryostats so an injection molded assembly which provides sufficient strength and low heat load may be difficult to incorporate in the design. In addition, the SSC design requires an intercept at $20 \mathrm{~K}$ which $\mathrm{RHIC}$ magnets do not utilize, further complicating the assembly. Finally, injection molded composite materials don't exhibit the combination of stiffness, strength, and low thermal conductivity required in the SSC collider dipole design.

It seems clear that a design alternate for reentrant support posts will be required for production dipoles primarily due to their cost. It seems less clear that injection molded composite materials are the ideal choice.

This report describes the conceptual design for a support post whose function is identical to that of the current reentrant design, which requires very few modifications to surrounding cryostat components, is at least structurally equivalent to the current $50 \mathrm{~mm}$ support post, and is nearly equivalent thermally. It is not intended to present a generic design for a single tube support. Rather its intent is to focus on a single tube support which is aimed specifically at application in SSC $50 \mathrm{~mm}$ collider dipoles.

\section{Design Overview}

The reentrant supports used in $40 \mathrm{~mm}$ and $50 \mathrm{~mm}$ SSC collider dipoles have shown themselves to be very capable of meeting their design requirements structurally and thermally, both in prototype magnets and in individual component tests. Filament wound tubes are superior to tubes fabricated from cloth layups or prepregs due to the ability, inherent in the filament winding process, to tailor the material properties in each of three principal directions. They are superior to injection molded tubes in strength and stiffness by virtue of their continuous fibers. Injection molded components either use chopped fibers randomly oriented in a resin matrix or a resin alone.

The method of joining the composite tubes to their metal end attachments in current reentrant supports has also proven very reliable over the broad temperature range to which the assemblies are subjected. Shrink fitting is used to capture the composite tubes between inner discs and outer flanges.2-5 Epoxy joints and other forms of mechanical bonding are less reliable when subjected to temperature extremes which range from $300 \mathrm{~K}$ to $4.5 \mathrm{~K}$. 
This is the starting point for the subject design. It utilizes filament wound composite tubes connected to metal end fittings and thermal intercepts via shrink fitting. The difference is that it no longer utilizes reentrant tubes and so contains fewer parts and is easier to assemble.

\section{Design Analysis}

The design analysis for this or any other suspension system component consists of two parts; estimation of both structural and thermal performance. In this case each is accomplished by separate finite element models which are parameterized to allow many different design options to be considered. Listings 1 and 2 contain the ANSYS input files for these two models as well as illustrations of their respective mesh plots. The structural model allows the deflections and stresses in the composite tubes to be estimated and compared with the design requirements and with the composite material properties. The thermal model allows heat loads to $80 \mathrm{~K}, 20 \mathrm{~K}$, and $4.5 \mathrm{~K}$ to be estimated and compared with the the heat load budget.

The first step in the design process was to determine something about the available physical envelope into which the new assembly must fit. The intent was not to launch into a completely new cryostat design, but rather to develop a replacement which required as few modifications to other components as possible. Using figure 1 as a reference, it is clear that there are real physical constraints on the design. A support which is too tall would require repositioning of the cold mass. One which is too large in diameter would require that the bottom shield segments and associated piping be repositioned or redesigned. However, taller, in and of itself, is desirable due to longer thermal path lengths. Larger in diameter typically yields tubes of greater stiffness. So it is important to maximize each and to estimate the resulting structural and thermal performance. The table below shows the approximate maximum assembly heights for each of four tube diameters which could readily be incorporated into the current cryostat design.

Table 1 - Support tube diameter v8. height

\begin{tabular}{c} 
Tube OD (in) \\
\hline 7 \\
8 \\
9 \\
10
\end{tabular}

\begin{tabular}{c} 
Allewable Height (in) \\
\hline 8.50 \\
8.25 \\
8.00 \\
7.75
\end{tabular}

Figures 3 and 4 illustrate typical heat loads to $80 \mathrm{~K}, 20 \mathrm{~K}$, and $4.5 \mathrm{~K}$ for each of these tube diameters assuming assemblies with equivalent maximum tube stresses. In each of these cases, the proportions of the thermal path to each intercept to the total available thermal length were kept constant. 
Using these results it is clear that the tube diameter should be maximized. An assembly which utilizes a ten inch diameter tube, or greater, would likely require extensive redesign of the cold mass cradle base and $80 \mathrm{~K}$ shield. A tube nine inches in diameter provides a good compromise between adequate thermal performance and minimum overall design modifications. Therefore, a single tube support assembly which utilizes a nine inch diameter tube will be the focus of the remaining analysis. The choice of even inch sizes serves only to limit the size of the design envelope. The final tube and assembly dimensions may be further optimized during the final design process.

The structural and thermal performance of this and all other superconducting magnet support systems are generally at odds with one another. Load and stiffness specifications imply materials with high strength. Low allowable heat loads imply good insulators which are typically not good structural materials. The goal of this or any such design is to strike a reasonable balance between the two.

After choosing a physical envelope, the tube wall thicknesses were determined. A single tube can be machined such that the wall thickness is optimized between thermal intercepts. Optimized in this case means that the actual stress in each section is nearly equal to the allowable strength of the material. For the two most likely candidate materials; S-glass in an epoxy matrix and graphite fiber in an epoxy matrix, these values are assumed to be 20000 psi and 30000 psi respectively. Given these and the design loads of $1.5 \mathrm{~g}$ lateral and $1.0 \mathrm{~g}$ vertical applied at the cold mass centerline, the thicknesses of the nine inch tube between each intercept were determined by iteratively solving the structural problem with each tube section length sized by rough estimates of their final lengths. The results of this process are shown in table 2 .

Table 2 - Wall thickness for each tube section

\begin{tabular}{cc} 
Tube section & Wall thickness (in) \\
\hline $300 \mathrm{~K}$ to $80 \mathrm{~K}$ & 0.110 \\
$80 \mathrm{~K}$ to $20 \mathrm{~K}$ & 0.090 \\
$20 \mathrm{~K}$ to $4.5 \mathrm{~K}$ & 0.080
\end{tabular}

Of the eight inch overall height available in the nine inch diameter tube case (see table 1), 5.5 inches are available for thermal paths. The remainder of the tube length is used by the top and bottom flanges $(0.75$ inch each) and by the $80 \mathrm{~K}$ and $20 \mathrm{~K}$ intercept rings ( 0.5 inch each). Using the above thicknesses, the optimum location of each intercept needs to be chosen to yield an assembly whose heat load is as close to the budget as possible.

Starting with the tube thicknesses in table 2, the assembly heights from table 1, and the available thermal path length, the next step is to proportion the total thermal path among the three operating temperature 
ranges; $300 \mathrm{~K}$ to $80 \mathrm{~K}, 80 \mathrm{~K}$ to $20 \mathrm{~K}$, and $20 \mathrm{~K}$ to $4.5 \mathrm{~K}$. It was clear during the development of the $40 \mathrm{~mm}$ dipole reentrant supports that fiberglass reinforced composite (FRP) was the material of choice between $300 \mathrm{~K}$ and $80 \mathrm{~K}$ and that graphite reinforced composite (GRP) was ideally suited for operation between $20 \mathrm{~K}$ and $4.5 \mathrm{~K}$. It was less clear which was preferred for use between $80 \mathrm{~K}$ and $20 \mathrm{~K}$. In the reentrant tube design, if GRP was used between $20 \mathrm{~K}$ and $4.5 \mathrm{~K}$, it was also required between $80 \mathrm{~K}$ and $20 \mathrm{~K}$ because the center tube is one continuous piece. For the sake of this exercise, we assume that even though the design utilizes a single tube, it is conceivable for it to contain sections with different fibers. Exactly how that is done is still under development.

Several iterations of the thermal analysis model (see listing 2) were performed in an attempt to determine the proper split of the total thermal path between each of the different tube sections. The results from these iterations are shown in table 3. Plots of these same data are shown in figures 5 through 7.

Table 3 - Thermal analysis iteration results

ERP/ERP/GRP ERP/FRP/ERP ERP/GRP/GRP

\begin{tabular}{|c|c|c|c|c|c|c|c|c|c|c|c|c|}
\hline IA & L20 & L80 & LTot & Q4.5 & 020 & Q80 & Q4.5 & Q20 & 080 & $\mathbf{Q 4 . 5}$ & 020 & 080 \\
\hline$\overline{0.6}$ & 2.2 & 2.7 & 5.5 & $\overline{0.058}$ & $0 . \overline{444}$ & $2 . \overline{961}$ & 0.079 & 0.423 & 2961 & 0.060 & 0.620 & 2.786 \\
\hline 0.8 & 2.1 & 2.6 & 5.5 & 0.049 & 0.479 & 3.066 & 0.070 & 0.458 & 3.066 & 0.051 & 0.665 & 2.882 \\
\hline 1.0 & 2.0 & 2.5 & 5. & 0.042 & 0.514 & 3.179 & 0.063 & 0.493 & 3.179 & 0.044 & 0.711 & 2.984 \\
\hline 1.2 & 1.9 & 2.4 & 5.5 & 0.038 & 0.550 & 3.301 & 0.057 & 0.530 & 3.300 & 0.039 & 0.760 & 3.093 \\
\hline 1.4 & 1.8 & 2.3 & 5 & 0.034 & 0.589 & 3.431 & 0.053 & 0.570 & 3.431 & 0.035 & 0.812 & 3.211 \\
\hline 1.6 & 1.7 & 2.2 & 5. & 0.031 & 0.631 & 3.572 & 0.049 & 0.613 & 3.572 & 0.032 & 0.870 & 3.338 \\
\hline 1.8 & 1.6 & 2.1 & 5.5 & 0.029 & 0.678 & 3.725 & 0.046 & 0.661 & 3.725 & 0.030 & 0.935 & 3.473 \\
\hline
\end{tabular}

L4: $\quad 20 \mathrm{~K}$ to $4.5 \mathrm{~K}$ thermal path length

L20: $80 \mathrm{~K}$ to $20 \mathrm{~K}$ thermal path length

L80: $300 \mathrm{~K}$ to $80 \mathrm{~K}$ thermal path length

LTot: Total thermal path length

FRP/FRP/GRP: FRP between $300 \mathrm{~K}$ and $80 \mathrm{~K}$, FRP between $80 \mathrm{~K}$ and $20 \mathrm{~K}$, GRP between $20 \mathrm{~K}$ and $4.5 \mathrm{~K}$.

FRP/FRP/FRP: FRP between $300 \mathrm{~K}$ and $80 \mathrm{~K}$, FRP between $80 \mathrm{~K}$ and $20 \mathrm{~K}$, FRP between $20 \mathrm{~K}$ and $4.5 \mathrm{~K}$.

FRP/GRP/GRP: FRP between $300 \mathrm{~K}$ and $80 \mathrm{~K}$, GRP between $80 \mathrm{~K}$ and $20 \mathrm{~K}$, GRP between $20 \mathrm{~K}$ and $4.5 \mathrm{~K}$

(All lengths are in inches)

(All heat loads are in watts)

For comparison, table 4 lists the current $50 \mathrm{~mm}$ dipole heat load budget and two calculated heat loads for the current $50 \mathrm{~mm}$ reentrant support. The first set of calculated values (Case 1) ignores the thermal resistance of the intercept straps and assumes that each of the $80 \mathrm{~K}$ and $20 \mathrm{~K}$ intercepts are perfectly heat sunk to their respective shields. The second 
(Case 2) includes the effect of thermal impedance in the intercept connections.

Table 4 - Current heat load budget and reentrant support predictions

$\begin{array}{llll} & \text { Budget } & \text { Case 1 } & \text { Case 2 } \\ \text { Heat load to 4.5K: } & 0.032 \mathrm{~W} & 0.033 \mathrm{~W} & 0.037 \mathrm{~W} \\ \text { Heat load to 20K: } & 0.480 \mathrm{~W} & 0.492 \mathrm{~W} & 0.609 \mathrm{~W} \\ \text { Heat load to 80K: } & 3.160 \mathrm{~W} & 3.133 \mathrm{~W} & 2.953 \mathrm{~W}\end{array}$

Two things are clear from figures 5 through 7 . First, in order to get close to the $4.5 \mathrm{~K}$ heat load budget, GRP must be used for the tube section between $20 \mathrm{~K}$ and $4.5 \mathrm{~K}$. Second, GRP in the $80 \mathrm{~K}$ to $20 \mathrm{~K}$ tube section does not allow the 20K heat load to be met. FRP is required for that section. A few fine tuning iterations yield the following proportions for the three tube sections.

Table 5 - Final thermal path proportions

$\begin{array}{rl}300 \mathrm{~K} \text { to } 80 \mathrm{~K}: & 2.50 \text { in } \\ 80 \mathrm{~K} \text { to } 20 \mathrm{~K}: & 1.75 \text { in } \\ 20 \mathrm{~K} \text { to } 4.5 \mathrm{~K} & 1.25 \text { in }\end{array}$

This proportioning yields the heat loads to each thermal stations shown in table 6 which include the thermal impedances of the cold mass cradle and intercept straps. Note that there is remarkably good agreement between these values and those in column three of table 4 (Case 2), i.e. this single tube support and the current reentrant support have almost identical predicted thermal performance. Table 6 also includes the heat load to each thermal station for an all FRP tube (FRP/FRP/FRP) for reference in the event that a means of fabricating a tube with S-glass and graphite fibers into the same structure can not be found.

Table 6 - Final heat loads for nine inch diameter single tube support

Heat load to $4.5 \mathrm{~K}$ :

Heat load to $20 \mathrm{~K}$ :

Heat load to 80K:

$\begin{array}{cc}\text { ERP/FRP/GRP } & \text { ERP/ERP/FRP } \\ 0.037 \mathrm{~W} & 0.056 \mathrm{~W} \\ 0.596 \mathrm{~W} & 0.576 \mathrm{~W} \\ 3.104 \mathrm{~W} & 3.104 \mathrm{~W}\end{array}$

(All heat loads are per support)

The structural analysis model using these final section lengths confirms that the stress constraints are still near their optimal values for the tube thicknesses shown in table 2. The stresses are shown in table 7 for the FRP/FRP/GRP assembly. 
Table 7 - Tube stresses in the final assembly configuration

$\begin{array}{lccc} & \sigma(\max \text { compr) } & \sigma(\max \text { tens }) & \tau(\max ) \\ \text { 300K to 80K section: } & -22815 & 19310 & 4836 \\ \text { 80K to 20K section: } & -25619 & 20999 & 6028 \\ \text { 20K to 4.5K section: } & -30599 & 25929 & 6707\end{array}$

(All stresses are in psi)

Recall that the $20 \mathrm{~K}$ to $4.5 \mathrm{~K}$ section is GRP which has an allowable tensile strength of 30000 psi vs. 20000 for FRP.

One thing remains troublesome and is indicated by the discrepancy between the calculated $20 \mathrm{~K}$ heat loads shown in the second and third columns of table 4. The discrepancy is caused by the thermal impedances in the $80 \mathrm{~K}$ and $20 \mathrm{~K}$ straps which increase the temperature at which each post intercept operates and drives the $20 \mathrm{~K}$ heat load upward. The thermal analysis model may equally well be u'sed to investigate this effect. The results from several analyses aimed at studying the sensitivity of heat load to strap cross section are shown in table 8. It assumes the final assembly geometry listed above. The current $80 \mathrm{~K}$ and $20 \mathrm{~K}$ straps connecting the intercepts to the shields are $0.1111 \mathrm{~cm}^{2} / \mathrm{cm}$ and $0.0444 \mathrm{~cm}^{2} / \mathrm{cm}$ respectively (cross section/length).

Table 8 - Sensitivity of heat load to thermal intercept impedance

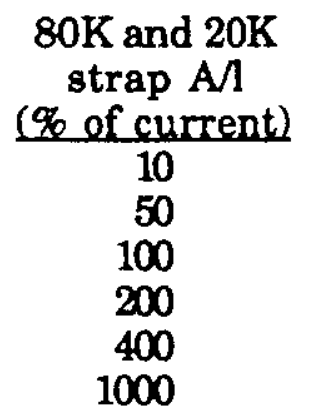
$4.5 \mathrm{~K}$
$0.135 \mathrm{~W}$
$0.042 \mathrm{~W}$
$0.037 \mathrm{~W}$
$0.035 \mathrm{~W}$
$0.034 \mathrm{~W}$
$0.033 W$

$20 \mathrm{~K}$
$0.913 \mathrm{~W}$
$0.651 \mathrm{~W}$
$0.596 \mathrm{~W}$
$0.567 \mathrm{~W}$
$0.552 \mathrm{~W}$
$0.537 \mathrm{~W}$

$80 \mathrm{~K}$

$2.220 \mathrm{~W}$

$2.984 \mathrm{~W}$

$3.104 \mathrm{~W}$

$3.166 \mathrm{~W}$

$3.197 \mathrm{~W}$

$3.228 \mathrm{~W}$

Clearly the heat loads to each intercept are affected by the size of the intercept straps. This serves not only to justify their existence, but also to stress the importance of good thermal connections between the straps, intercepts, and shields.

\section{Final Dimensional and Performance Parameters}

Table 9 lists some of the dimensional and performance parameters for the single tube support described in this report as well as comparable values for the current $50 \mathrm{~mm}$ support post design. Figure 8 illustrates a cross section through the proposed support. 
Table 9 - Final dimensional and performance parameters

$300 \mathrm{~K}$ to $80 \mathrm{~K}$

OD:

thickness:

thermal path length:

material:

max tensile stress:
Single tube support

9.0 in

0.110 in

2.5 in

FRP

$19310 \mathrm{psi}$

9.0 in

0.090 in

1.75 in

FRP

20999 psi

max tensile stress:

$20 \mathrm{~K}$ to $4.5 \mathrm{~K}$

OD:

thickness:

thermal path length:

material:

max tensile stress:

Overall assembly height:

Cold mass deflection:

Heat load to $4.5 \mathrm{~K}$ :

Heat load to $20 \mathrm{~K}$ :

Heat load to $80 \mathrm{~K}$ :
9.0 in

0.080 in

1.25 in

GRP

25929 psi

8.0 in

0.126 in

$0.037 \mathrm{~W}$

$0.596 \mathrm{~W}$

$3.104 \mathrm{~W}$
Reentrant support
9.5 in
0.085 in
2.5 in
FRP
$18900 \mathrm{psi}$

As mentioned previously, there is some flexibility in the design envelope for the single tube support. More detailed design analysis may yield parameters somewhat different than those listed above. These, however, serve as a good starting reference.

One final note about machining tolerances is warranted here. As noted in the introduction to this report, one of the factors driving the cost of the reentrant supports is the close tolerancing required to effect the shrink fit joints. Figure 9 contains the results from an analysis program which is used to predict the required interference in these joints. These results are for the $300 \mathrm{~K}$ joint of the proposed single tube support, i.e. that with the highest overturning moment. The first section of this table indicates that the total radial interference required to just meet the structural requirement for this joint is 0.0068 inch. The second section shows the same joint with 0.0108 inch interference, i.e. the results for a 0.004 inch wide radial tolerance band. This listing illustrates the joint sensitivity to 
the effective interference. It must be sufficient to meet the mechanical specifications, but not so high as to overstress the metal parts.

Close tolerancing will still be required in the single tube design. It is hoped that by machining the composite tubes with lands at which close tolerances are required rather than requiring that the entire length be tightly controlled will reduce the difficulties encountered by composite tube suppliers thus far in the $40 \mathrm{~mm}$ and $50 \mathrm{~mm}$ development programs. Also, in large quantities, parts matching techniques may enable tolerances to be loosened up on both the metal and composite parts.

\section{Summary and Conclusions}

The above analysis indicates that a support post fabricated from a single composite tube can meet the structural and thermal specifications proposed for the SSC $50 \mathrm{~mm}$ collider dipole suspension system. Figure 10 illustrates the same $50 \mathrm{~mm}$ dipole cross section shown in figure 1, but which utilizes the single tube support described above.

Initial estimates from one vendor familiar with assembly of reentrant supports indicate that the total cost of a single tube support in quantities like those procured to date in the $50 \mathrm{~mm}$ prototype program would be on the order of $\$ 1700$, compared with $\$ 2500$ for the reentrant supports.

A test program has yet to be initiated which confirms the predicted performance of this assembly. Also, development work needs to be done to determine whether or not it is feasible to fabricate a single tube with both $\mathrm{S}$ glass and graphite fibers in the same structure. Filament winding or resin transfer molding may both be viable fabrication techniques.

It is possible that development work at the SSCL or at one of the industrial contractors will yield a support structure which successfully utilizes injection molded materials. The above analysis is one more alternative and one which is based firmly on proven design concepts. 


\section{References}

1. Superconducting Super Collider Laboratory, "15 Meter Collider Dipole Magnet Prime Development Specification," March 6, 1990.

2. Nicol, T.H., et al., "A Suspension System for Superconducting Super Collider Magnets," Proceedings of the Eleventh International Cryogenic Engineering Conference, Vol. 11, Butterworths, Surrey, UK, 1986, pp. 533-536.

3. Nicol, T.H., et al., "SSC Magnet Cryostat Suspension System Design," Advances in Cryogenic Engineering, Vol. 33, Plenum Press, New York, 1987 pp. 227-234.

4. Nicol, T.H., J.D. Gonczy and R.C. Niemann, "Design and Analysis of the SSC Dipole Magnet Suspension System," Super Collider 1, Vol. 1, Plenum Press, New York, 1989, pp. 637-649.

5. Nicol, T.H., "SSC 50mm Collider Dipole Cryostat Design," presented at the $1991 \mathrm{CEC/ICMC} \mathrm{Conference,} \mathrm{Huntsville,} \mathrm{AL,} \mathrm{June} \mathrm{11-14,} 1991$.

6. Wolf, L.J. and J. Sondericker, “Alternative Concepts for Structurally Supporting the Cold Mass of Superconducting Accelerator Magnets", presented at the 1991 IISSC Conference, Atlanta, GA, March 13-15, 1991. 


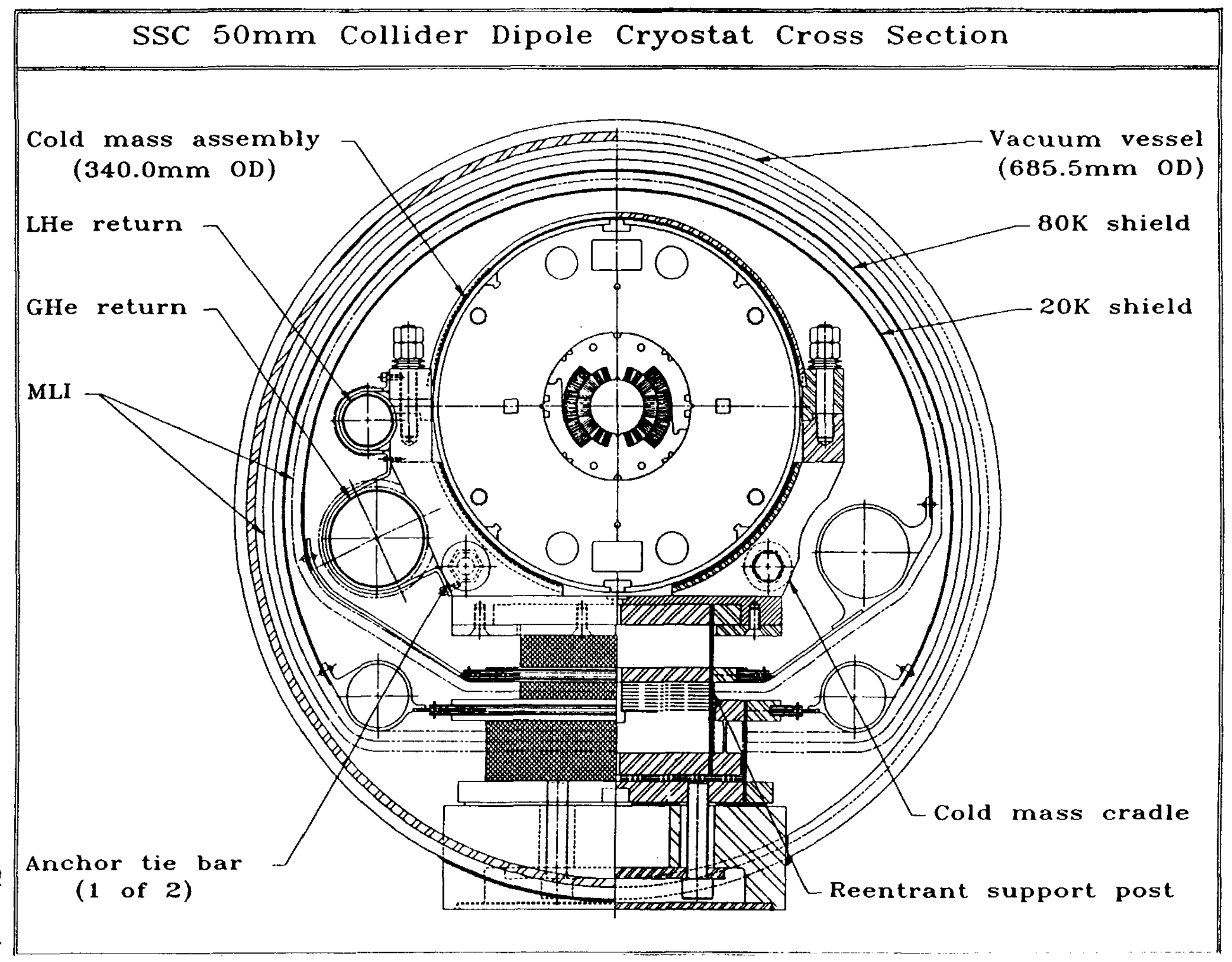


SSC 50mm Single Tube Support 4.5K Heat Load vs. Tube Diameter

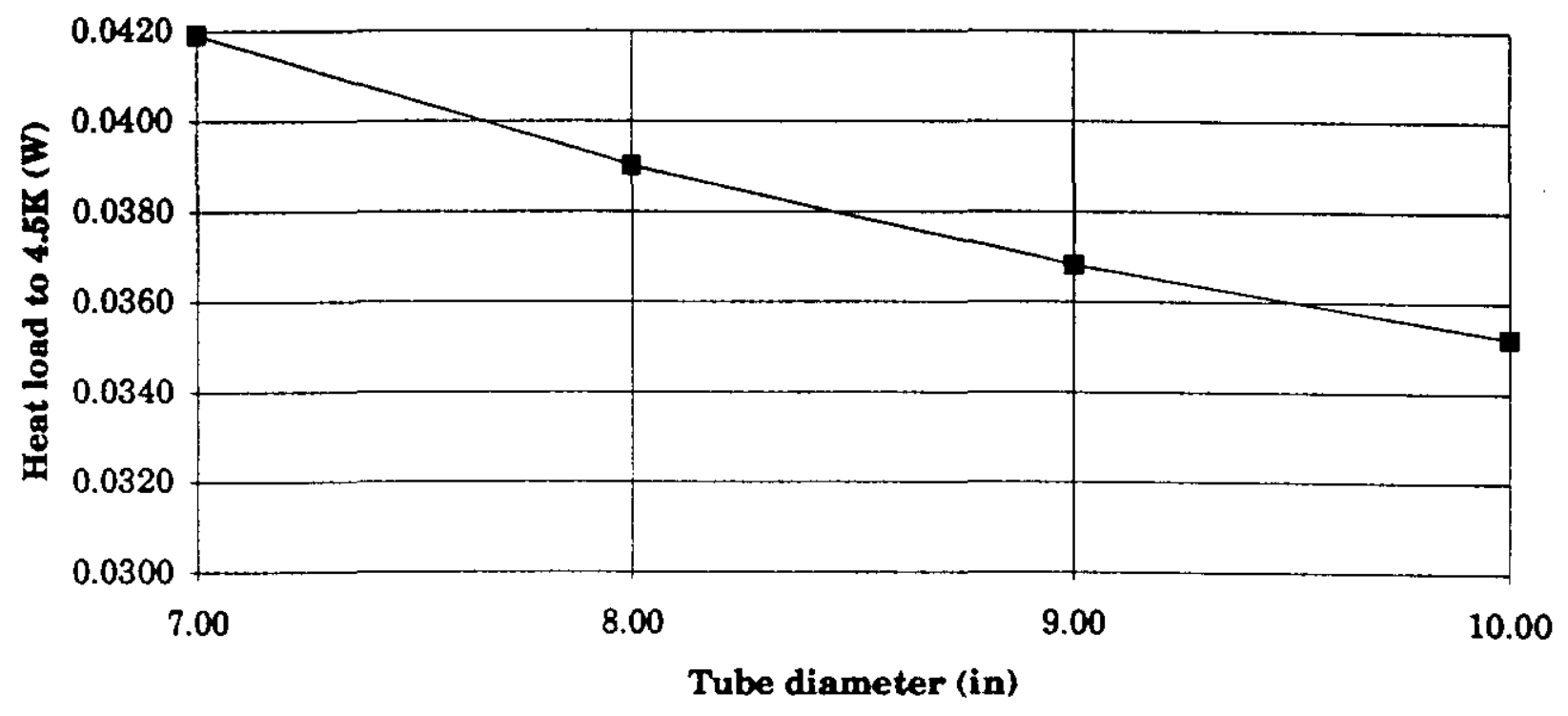

Figure 3 
SSC 50mm Single Tube Support 20K and 80K Heat Load vs. Tube Diameter

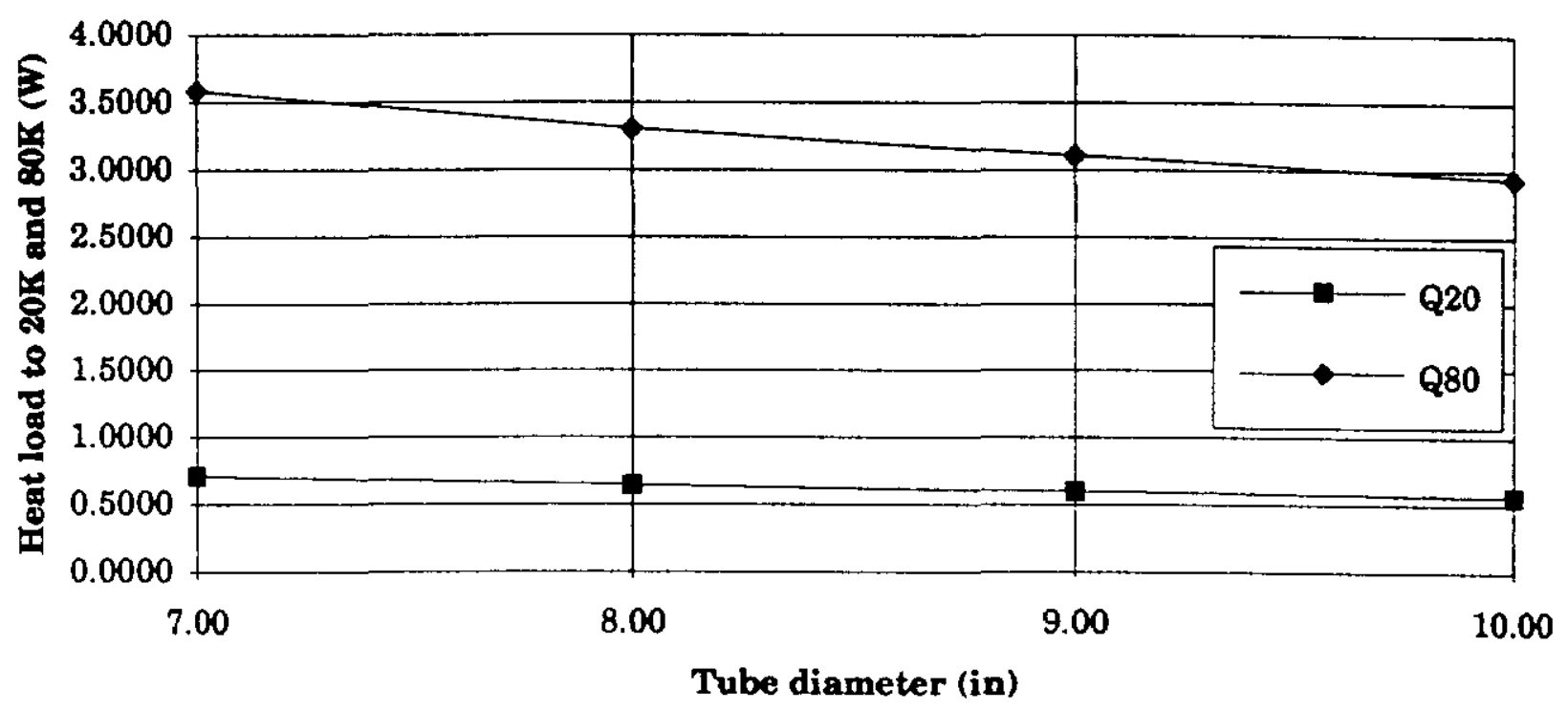

Figure 4 
SSC 50mm Single Tube Support 4.5K Heat Load vs. Thermal Path Length

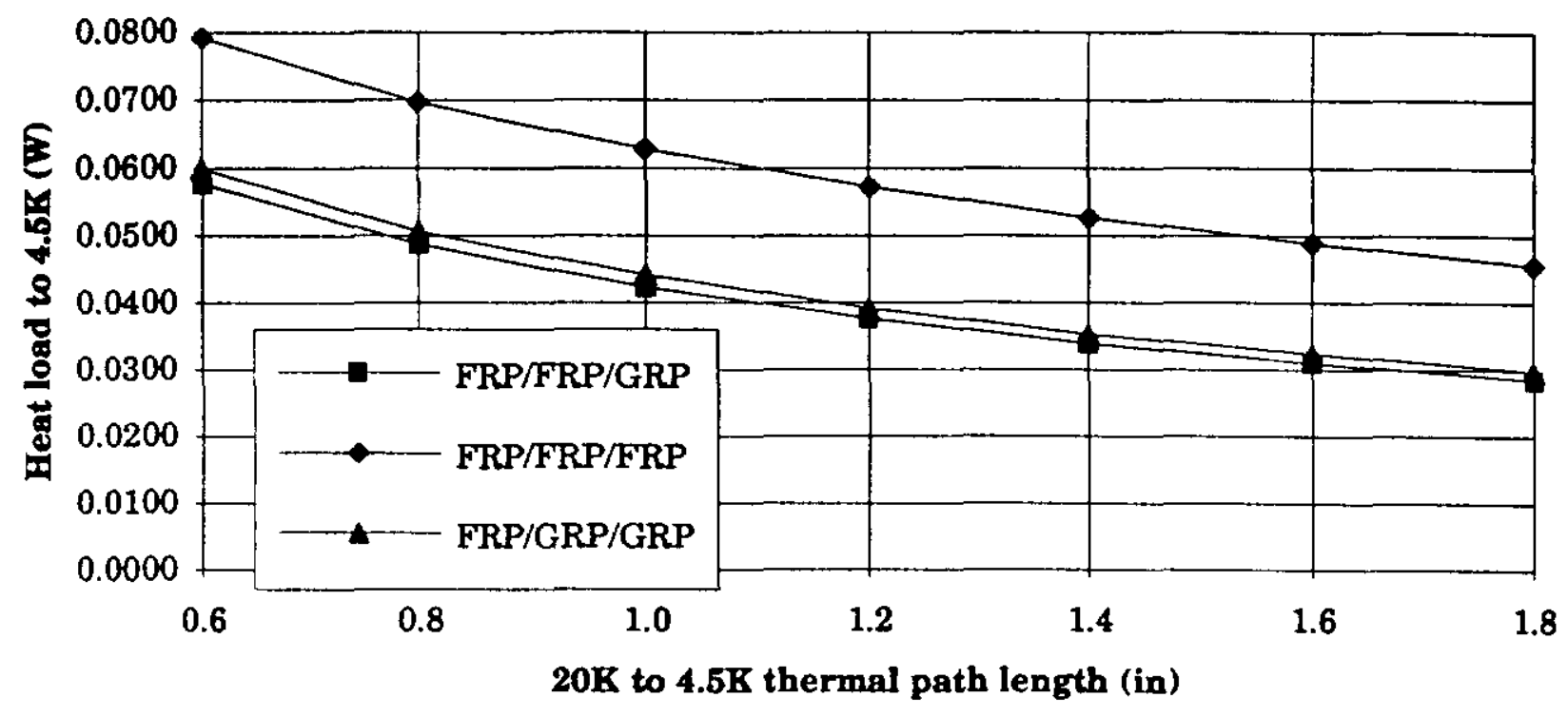


SSC 50mm Single Tube Support 20K Heat Load vs. Thermal Path Length

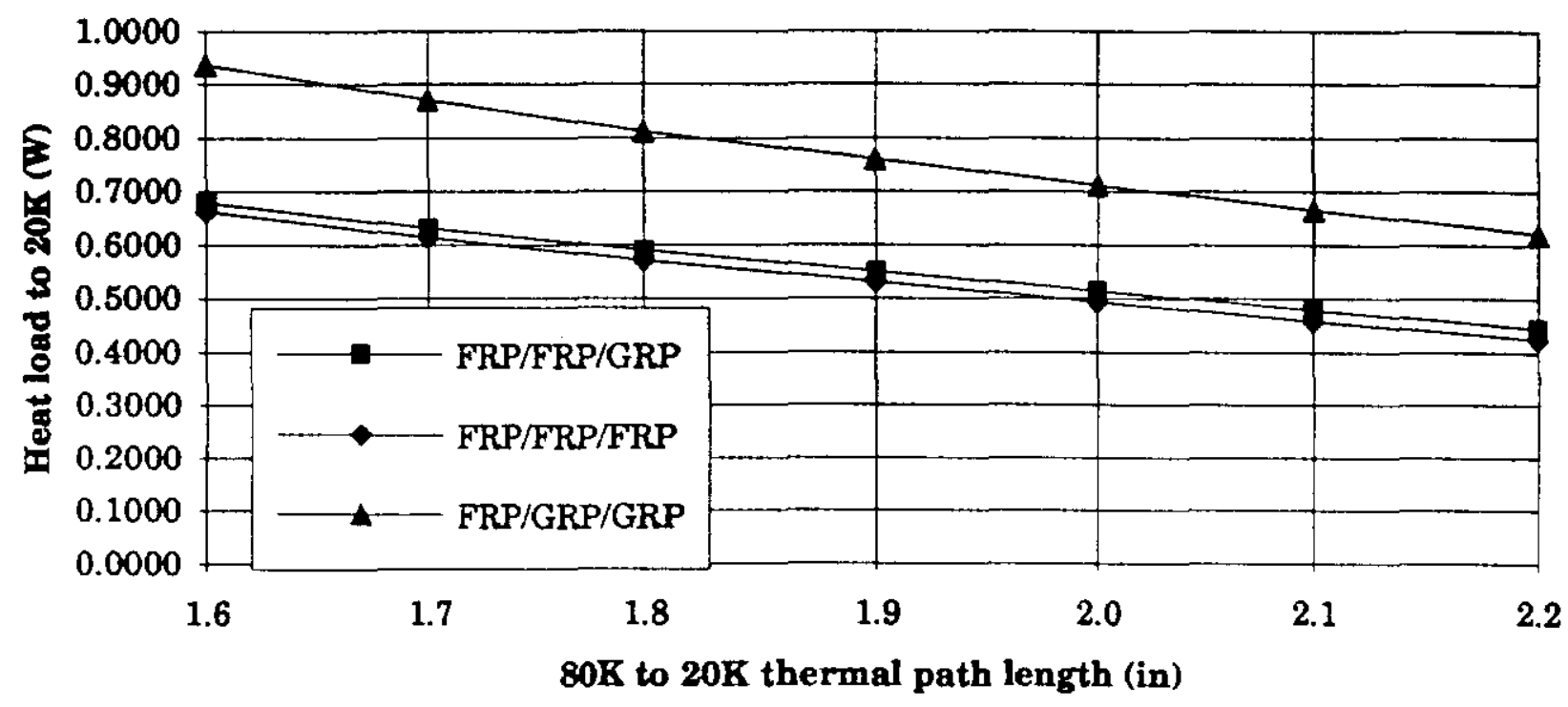

Figure 6 
SSC 50mm Single Tube Support 80K Heat Load vs. Thermal Path Length

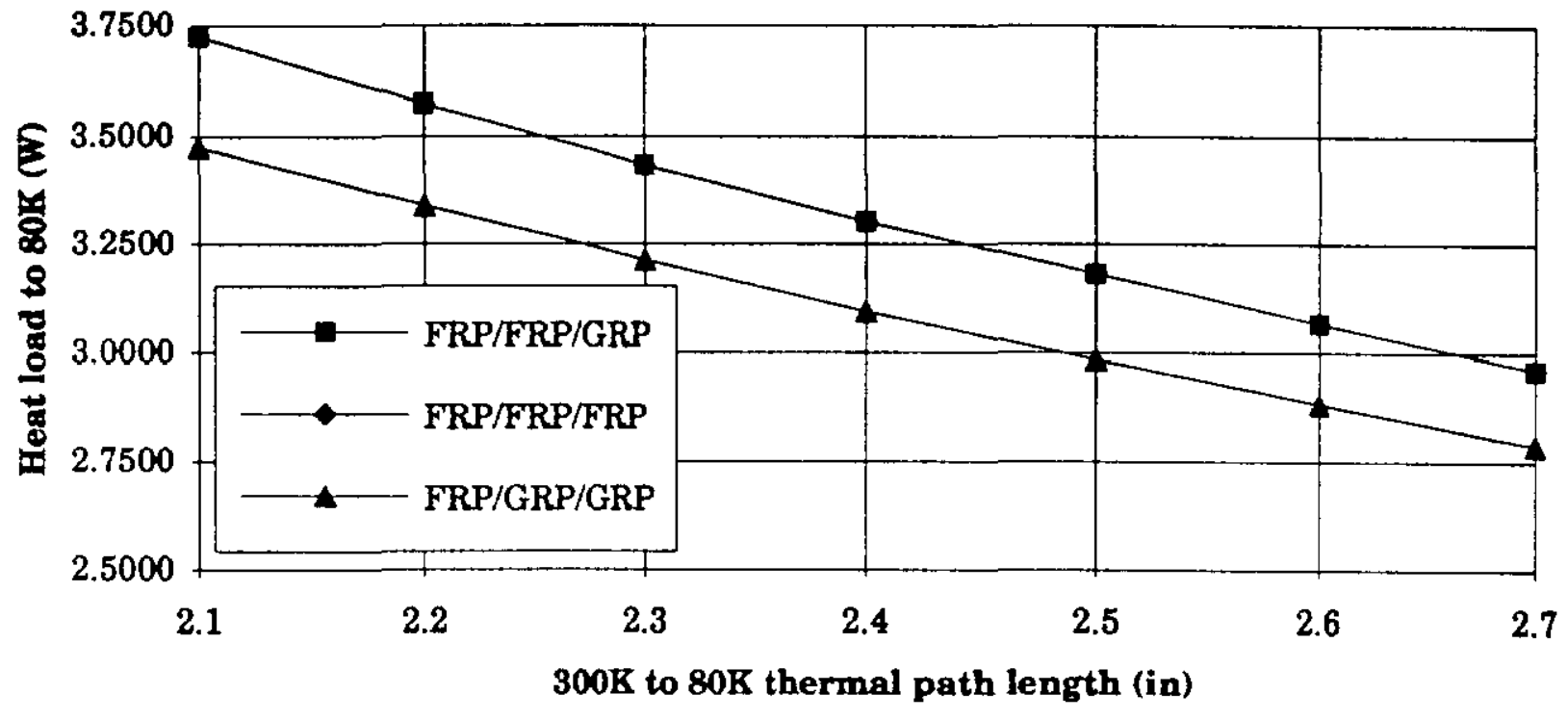

Figure 7 


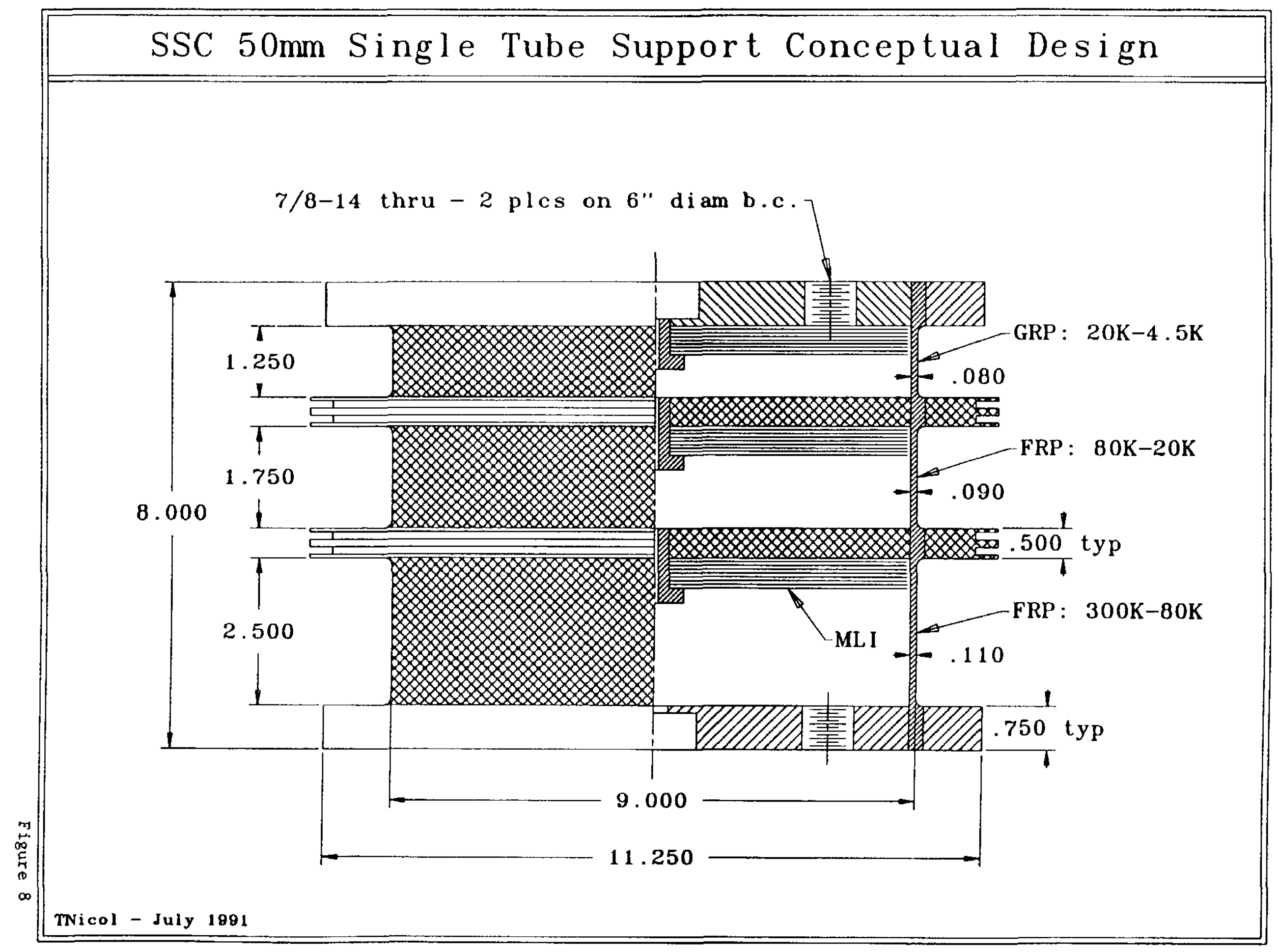


Note..................

Dimension, $A \ldots \ldots \ldots \ldots \ldots$ (in):

B............ (in) :

C........... (in):

D............. (in):

T.......... (in):

Material property, El......(psi):

v1........

E2.....(psi):

$\mathrm{v} 2 \ldots \ldots \ldots$ :

E3......(psi):

V3.........

Friction coefficient, Mu........

Force to slip, FSlip........(1b):

Resisting Moment, MRes...(in-1b):
$50 \mathrm{~mm}$ single tube support - $300 \mathrm{~K}$ joint .7500

4.3900

4.5625

5.5625

.7500

$.28 E+08$

.3330

$.10 E+07$

.2000

$.28 E+08$

.3330

.3000

.0

104666.0

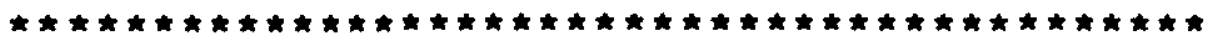

$\star \star \star \star \star *$ Shrink rit Analysis... Results $\star \star \star \star \star * *$

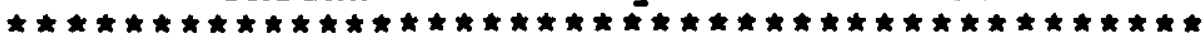

Interference reqd at inner interface...(in): $\quad 00325$

outer interface...(in): $\quad-.0256$

Total radial interference reqd.......(in): $\quad .0068$

Contact pressure at inner interface...(psi): 6034.4

outer interface...(psi): $\quad 5586.7$

Actual force to slip................ (1b): 37450.8 resisting moment.........(in-lb): $104666.0^{\star}$

\begin{tabular}{|c|c|c|c|}
\hline & $\begin{array}{l}\mathrm{Ri} \\
=======\end{array}$ & $\begin{array}{l}\mathrm{Rm} \\
========\end{array}$ & $\begin{array}{c}\text { Ro } \\
=======\end{array}$ \\
\hline 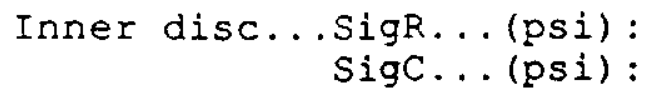 & $\begin{array}{r}.0 \\
-12431.6\end{array}$ & $\begin{array}{l}-5686.5 \\
-6745.2\end{array}$ & $\begin{array}{l}-6034.4 \\
-6397.2\end{array}$ \\
\hline 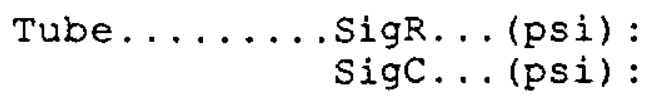 & $\begin{array}{r}-6034.4 \\
6034.4\end{array}$ & $\begin{array}{r}-5804.1 \\
5804.1\end{array}$ & $\begin{array}{r}-5586.7 \\
5586.7\end{array}$ \\
\hline $\begin{array}{r}\text { Outer ring... SigR...(psi): } \\
\text { SigC...(psi): }\end{array}$ & $\begin{array}{l}-5586.7 \\
28558.7\end{array}$ & $\begin{array}{l}-2380.9 \\
25352.8\end{array}$ & 22972.0 \\
\hline
\end{tabular}
}


Note.................

Dimension, A............. (in):

B........... in $:$

C............. in):

D............ (in):

T............... (in):

Material property, El......(psi):

v1.........

E2..... (psi):

v2.........

E3.....(psi):

V3.........

Friction coefficient, Mu........

Force to slip, ESIip......... (lb):

Resisting Moment, MRes...(in-lb):
$50 \mathrm{~mm}$ single tube support $-300 \mathrm{~K}$ joint .7500

4.3900

4.5625

5.5625

.7500

$.28 \mathrm{E}+08$

.3330

$.10 \mathrm{E}+07$

.2000

$.28 \mathrm{E}+08$

.3330

.3000

.0

165000.0

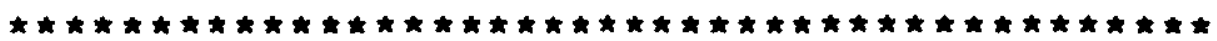

$\star \star \star \star *$ Shrink Fit Analysis...Results $\star * \star * *$

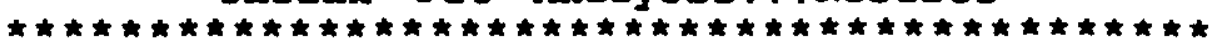

Interference reqd at inner interface...(in): 0512

outer interface...(in): $\quad-.0404$

Total radial interference reqd........(in): .0108

Contact pressure at inner interface...(psi): 9512.9 outer interface...(psi): $\quad 8807.2$

Actual force to slip................. (1b): 59039.0 resisting moment.........(in-1b): $165000.0^{\star}$

\begin{tabular}{|c|c|c|c|c|}
\hline & & $\begin{array}{c}\mathrm{Ri} \\
=== \pm====\end{array}$ & $\begin{array}{c}\mathrm{Rm} \\
=== \pm===\end{array}$ & $\begin{array}{c}\text { Ro } \\
======\end{array}$ \\
\hline Inner & $\begin{array}{r}\text { disc... } \operatorname{sigR\ldots } \ldots(p s i): \\
\operatorname{sigC\ldots } \ldots(p s i):\end{array}$ & $\begin{array}{r}.0 \\
-19597.8\end{array}$ & $\begin{array}{r}-8964.4 \\
-10633.4\end{array}$ & $\begin{array}{r}-9512.9 \\
-10084.9\end{array}$ \\
\hline Who & $\begin{array}{r}\ldots \ldots \text { sigR } \ldots(p s i): \\
\quad \operatorname{sigC} \ldots(p s i):\end{array}$ & $\begin{array}{r}-9512.9 \\
9512.9\end{array}$ & $\begin{array}{r}-9149.8 \\
9149.8\end{array}$ & $\begin{array}{r}-8807.2 \\
8807.2\end{array}$ \\
\hline uter & $\begin{array}{r}\text { ring...sigR .... (psi) } \\
\text { sigC ... (psi) }\end{array}$ & $\begin{array}{l}-8807.2 \\
45021.1\end{array}$ & $\begin{array}{l}-3753.3 \\
39967.3\end{array}$ & 36214.0 \\
\hline
\end{tabular}

*: Resisting moment sized to yield nominal interference +0.004 in
} 


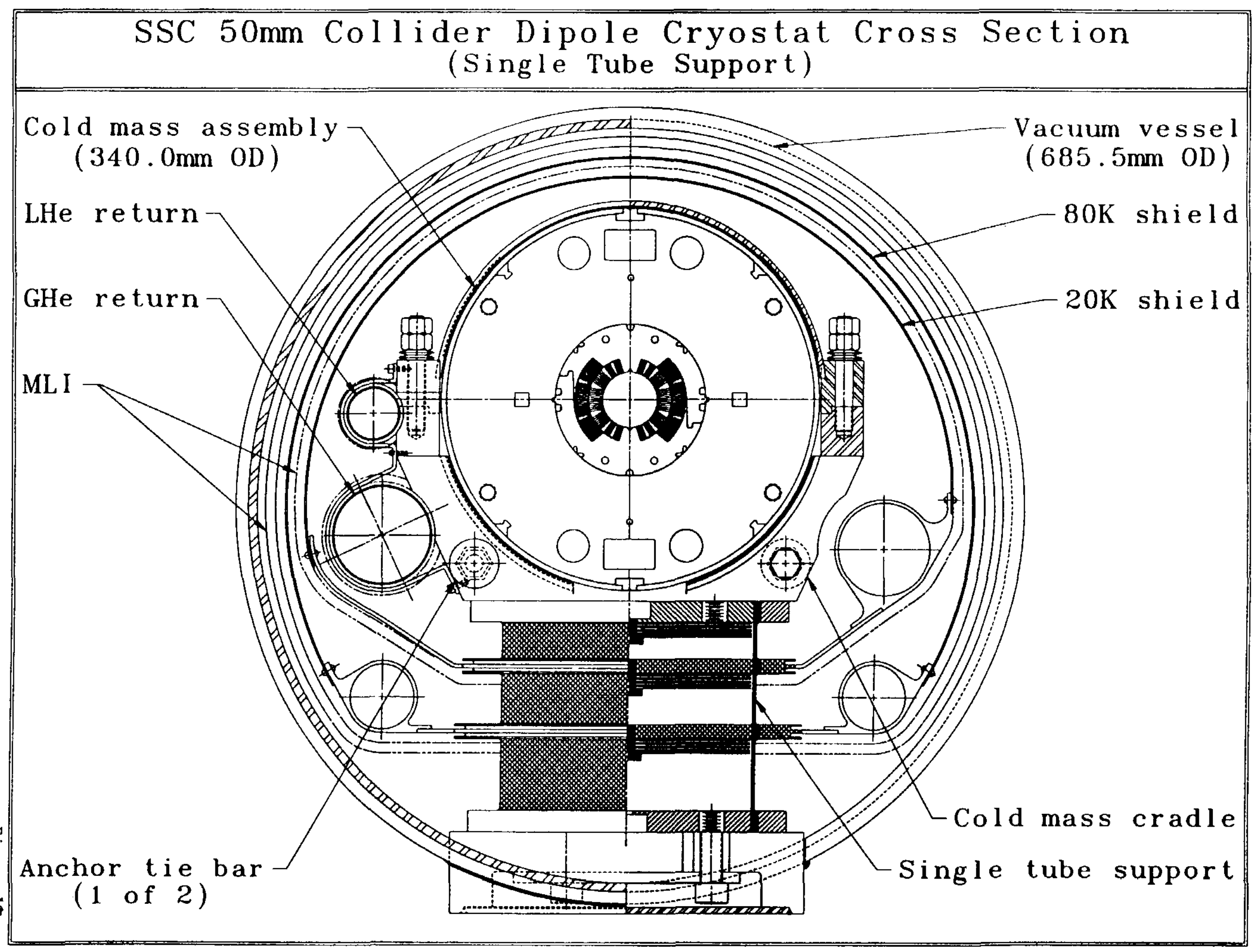


/TITLE,SSC 50mm single tube support - structural model - July 1991

/NOPR

$C * * *$

$C * * * * * * * * * * * * * * * * * * * * * * * * * * * * *$

C*** T. Nicol - Fermilab ****

C*** July 1991 ****

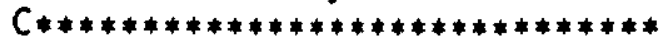

$C * * *$

C*** Filename: $50 \mathrm{~mm}$ single_tube_structural .026

$C * * *$

C*** This is a structural model for an SSC style support post which utilizes

C*** a single support tube as opposed to two reentrant tubes like those from

C*** the $40 \mathrm{~mm}$ and $50 \mathrm{~mm}$ development programs. I can accommodate different

C*** wall thicknesses, and materials for each tube section, i.e. $300 \mathrm{~K}$ to $80 \mathrm{~K}$,

C*** 8OK to 20K, and 20K to 4.5K.

$C * * *$

C*** Refer to log book \$10, pages 225-231 for model development ****

$C * * *$

/SHOW, X11

/VIEV, $1,3.0,4.0,5.0$

TD8C , 1

RDBC, 1

FBC, 1

$C * * *$

C*** Define variable parameters ****

$C * * *$

*SET, $L, 8.0$

*SET, F80, 43.75

*SET, F20, 28.125

*SET, F4, (100.0-F80-F20)

*SET, OD, 9.0

*SET, T1, 0.110

*SET, T2, 0.090

*SET, T3,0.080

*SET, HCG , 14.125

*SET, R1 , 1.0

*SET, R2, (0D/2.0)

* Overall hoight...

* Fraction of total length from 300K to $80 \mathrm{~K} .$.

* Fraction of total length from $80 \mathrm{~K}$ to $20 \mathrm{~K} . .$.

*SET, L1, $(L *(F 80 / 100.0))$ * Length from 300K to $80 \mathrm{~K} . .$.

*SET,L2, (L*(F20/100.0)) * Length from 80K to 20K...

*SET, L3, $(L *(F 4 / 100.0))$ * Length from 20K to $4 \mathrm{~K} .$.

*SET, FG, 7410.0

*SET, FW, 4940.0

*SET, FQ, 0.0

*SET, FT1 0.75

*SET, FT2, 0.5

*SET, FT3,0.5

*SET, FT 4, 0.75

* Fraction of total length from $20 \mathrm{~K}$ to $4 \mathrm{~K} . .$.

* Tube 00...

- Tube thickness 1 (300K to 80K)...

* Tube thickness 2 (80K to 20K)...

* Tube thickness 3 (20K to 4K) ...

* Height of cold mass $\mathrm{cg} .$.

* Disc inner radius...

* Tube radius...

* Length from 20K to

* Vertical weight load...

* Lateral quench load...

* Flange thickness 1 (300K)...

* Flange thickness 2 (80K)...

* Flange thickness 3 (20K)...

*SET, FW1, 1.0

* Flange thickness 4 (4K) ...

*SET, FW2, 1.0

* Flange width 1 (300K)...

*SET, FW3, 1.0

*SET, FW4, 1.0

* Flange width 2 (80K)...

* Flange width 3 (2OK)...

* Flange width 4 (4K)...

$C * * *$

$C * * *$ Define analysis type ****

$C * * *$

KAN, 0

$C * * *$

$C * * *$ Define element types $* * * *$

$C * * *$

$E T, 1,63 * 3$-d quadrilateral shells... 
$E T, 2,45$ *3-d i soparametric solids...

ET, 3,4 * 3-d beams...

$C * * *$

C*** Define material properties ****

$C * * *$

EX,1,4.0E6

- 300K to $80 \mathrm{~K}$ tube...

MUYY, $1,0.2$

GXY, 1,0.380E6

$E X, 2,4.0 E 6$

* 80K to $20 \mathrm{~K}$ tube...

NUXY, 2,0.2

GXY, $2,0.380 E 6$

$E X, 3,8.0 E 6$

MXY, 3,0.2

*20K to $4 \mathrm{~K}$ tube...

GXY, 3,0.380E6

EX, 4, 28.0E6

MXYY, $4,0.3$

EX, 5, 10.0E6

- Stainless steel...

MXY, 5,0.3

$E X, 6,30.0 E 6$

- Aluminum. .

MXY, 6,0.3

$C * * *$

C*** Define real constants

$C * * *$

$R, 1, T 1$

$R, 2, T 2$

$R, 3, T 3$

$R, 4,0.0$

* Steel...

$R, 5,10.0,1000.0,1000.0,10.0,10.0$

* 300K to $80 \mathrm{~K}$ tube...

* 80K to $20 \mathrm{~K}$ tube...

* 20K to $4 K$ tube...

C***

C*** Define nodes ****

$C * * *$

$C * * *$ Tube

* Discs and rings...

* Beams (arbitrarily

$C * * *$

CSYS, 0

$N, 1, R 2,0.0$

$N, 3, R 2, F T 1$

$N, 23, R 2,(L 1-F T 2 / 2)$

$\mathrm{N}, 25, \mathrm{R} 2,(\mathrm{~L} 1+\mathrm{FT} 2 / 2)$

$\mathrm{N}, 45, \mathrm{R2},(\mathrm{L} 1+\mathrm{L} 2-\mathrm{FT} 3 / 2)$

$N, 47, R 2,(L 1+L 2+F T 3 / 2)$

$N, 57, R 2,(L-F T 4)$

$N, 59, R 2, L$

FILL, 1,3

FILL, 3,23

FILL, 23, 25

FILL, 25, 45

FILL, 45, 47

FILL, 47,57

FILL, 57,59

$C * * *$

$C * * *$ Discs and flanges

C****

$C * * * 300 K * * * *$

$C * * *$

$N, 101, R 1,0.0$

$N, 103, R 1, F T 1$

$N, 113, R 2,0.0$

$N, 115, R 2, F T 1$

FILL, 101, 103

FILL, 113,115 
FILL , 101, 113,3

RP3 $1,1,0$

$N, 151, R 2,0.0$

$N, 153, R 2, F T 1$

$N, 157,(R 2+F W 1), 0.0$

$N, 159,(R 2+F W 1), F T 1$

FILL, 151, 153

FILL, 157, 159

FILL, 151, 157, 1

RP3 $1,1,0$

C***

$C * * * 80 K$

$\mathrm{C} * * *$

$\mathrm{N}, 201, \mathrm{R} 1,(\mathrm{~L} 1-\mathrm{FT} 2 / 2)$

$\mathrm{N}, 203, \mathrm{R1},(\mathrm{L} 1+\mathrm{FT} 2 / 2)$

$N, 213, R 2,(L 1-F T 2 / 2)$

$N, 215, R 2,(L 1+F T 2 / 2)$

FILL, 201, 203

FILL, 213, 215

FILL, 201, 213, 3

RP3 $1,1,0$

$N, 251, R 2,(L 1-F T 2 / 2)$

$N, 253, R 2,(L 1+F T 2 / 2)$

$N, 257,($ R2+FW2), (L1-FT2/2)

$N, 259,(R 2+F W 2),(L 1+F T 2 / 2)$

FILL, 251, 253

FILL, 257, 259

FILL, 251, 257, 1

RP3, 1, 1,0

C****

C*** 2OK ****

$C * * *$

$N, 301, R 1,(L 1+L 2-F T 3 / 2)$

$\mathrm{N}, 303, \mathrm{R1},(\mathrm{L} 1+\mathrm{L} 2+\mathrm{FT} 3 / 2)$

$\mathrm{N}, 313, \mathrm{R2},(\mathrm{L} 1+\mathrm{L} 2-\mathrm{FT} 3 / 2)$

$N, 315, R 2,(L 1+L 2+F T 3 / 2)$

FILL, 301, 303

FILL, 313, 315

FILL, 301, 313, 3

RP3 $, 1,1,0$

$N, 351, R 2,(L 1+L 2-F T 3 / 2)$

$\mathrm{N}, 353, \mathrm{R} 2,(\mathrm{~L} 1+\mathrm{L} 2+\mathrm{FT} 3 / 2)$

$N, 357,(R 2+F W 3),(L 1+L 2-F T 3 / 2)$

$\mathrm{N}, 359,(\mathrm{R} 2+\mathrm{F} W 3),(\mathrm{L} 1+\mathrm{L} 2+\mathrm{FT} 3 / 2)$

FILL, 351,353

FILL, 357, 359

FILL, 351, 357, 1

RP3, 1, 1, 0

$C * * *$

$C * * * 4 K \quad * * * *$

$C * * *$

$N, 401, R 1,(L-F T 4)$

$N, 403, R 1, L$

$N, 413, R 2,(L-F T 4)$

$N, 415, R 2, L$

FILL, 401, 403

FILL, 413, 415

FILL, 401, 413, 3

RP3, 1, 1, 0

$N, 451, R 2,(L-F T 4)$ 


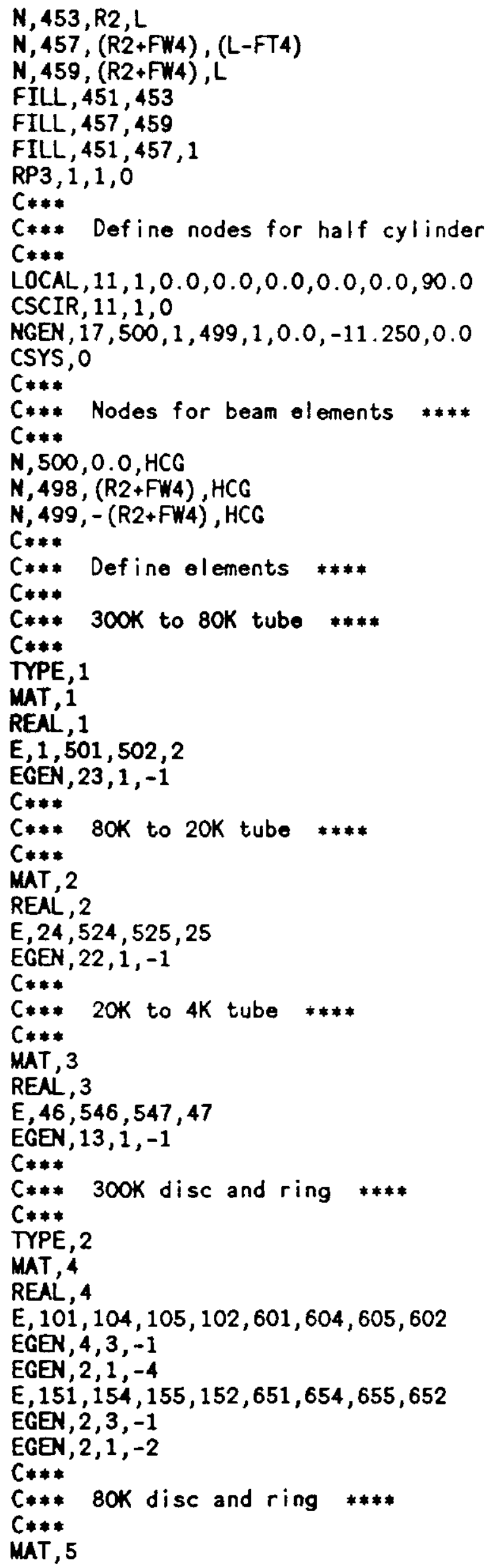




\section{REAL, 4}

E, 201, 204, 205, 202, 701, 704, 705, 702

ECEN, $4,3,-1$

EGEN, $2,1,-4$

$E, 251,254,255,252,751,754,755,752$

EGEN, 2, 3, -1

EGEN $, 2,1,-2$

$C * * *$

$C * * * 20 K$ disc and ring ****

$C * * *$

MAT, 5

REAL, 4

$E, 301,304,305,302,801,804,805,802$

EGEN , 4, 3, -1

EGEN, $2,1,-4$

$E, 351,354,355,352,851,854,855,852$

EGEN , 2,3,-1

EGEN, 2,1,-2

$C * * *$

$C * * * 4 K$ disc and ring

C***

MAT, 4

REAL, 4

E, 401, 404, 405, 402,901, 904,905,902

ECEN , 4, 3, -1

EGEN, 2,1,-4

$E, 451,454,455,452,951,954,955,952$

EGEN, 2, 3, -1

EGEN, $2,1,-2$

$C * * *$

C*** Generate elements around half-cylinder

$C * * *$

EGEN, 16,500, -999

$C * * *$

C*** Beams to simulate cradle assy ****

$C * * *$

TYPE, 3

MAT, 6

REAL, 5

$E, 459,498$

$E, 498,500$

$E, 500,499$

$E, 499,8459$

$C * * *$

$C * * *$ Merge nodes and reorder wavefront ****

$C * * *$

MMMRG, NODE, 0.001

WSORT, $Y, O$

$C * * *$

C*** Define boundary conditions ****

$C * * *$

SYMBC, 0,3

$D, 104, A L L, 0.0,8104,500$

* Symmetry at $x y-p l a n e .$.

$D, 107, A L L, 0.0,, 8107,500$

$0,110, A L L, 0.0,, 8110,500$

\section{C***}

C*** Define forces ****

C****

$F, 500, F X,(F G / 2.0)$

$F^{\prime}, 459, F Y,(-F W / 2.0 / 17.0),, 8459,500$

* Lateral g-load...

* Fixed base... 


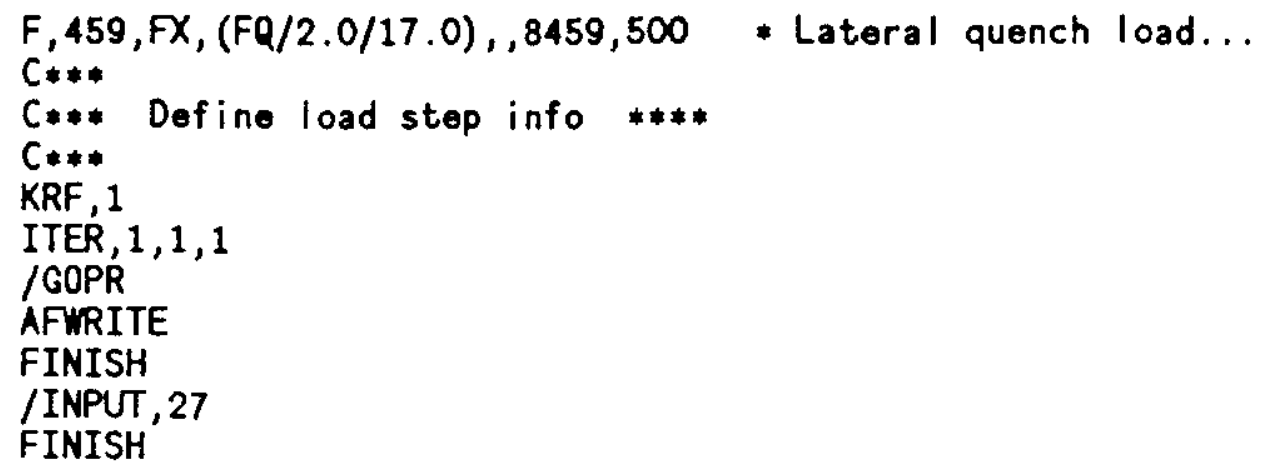




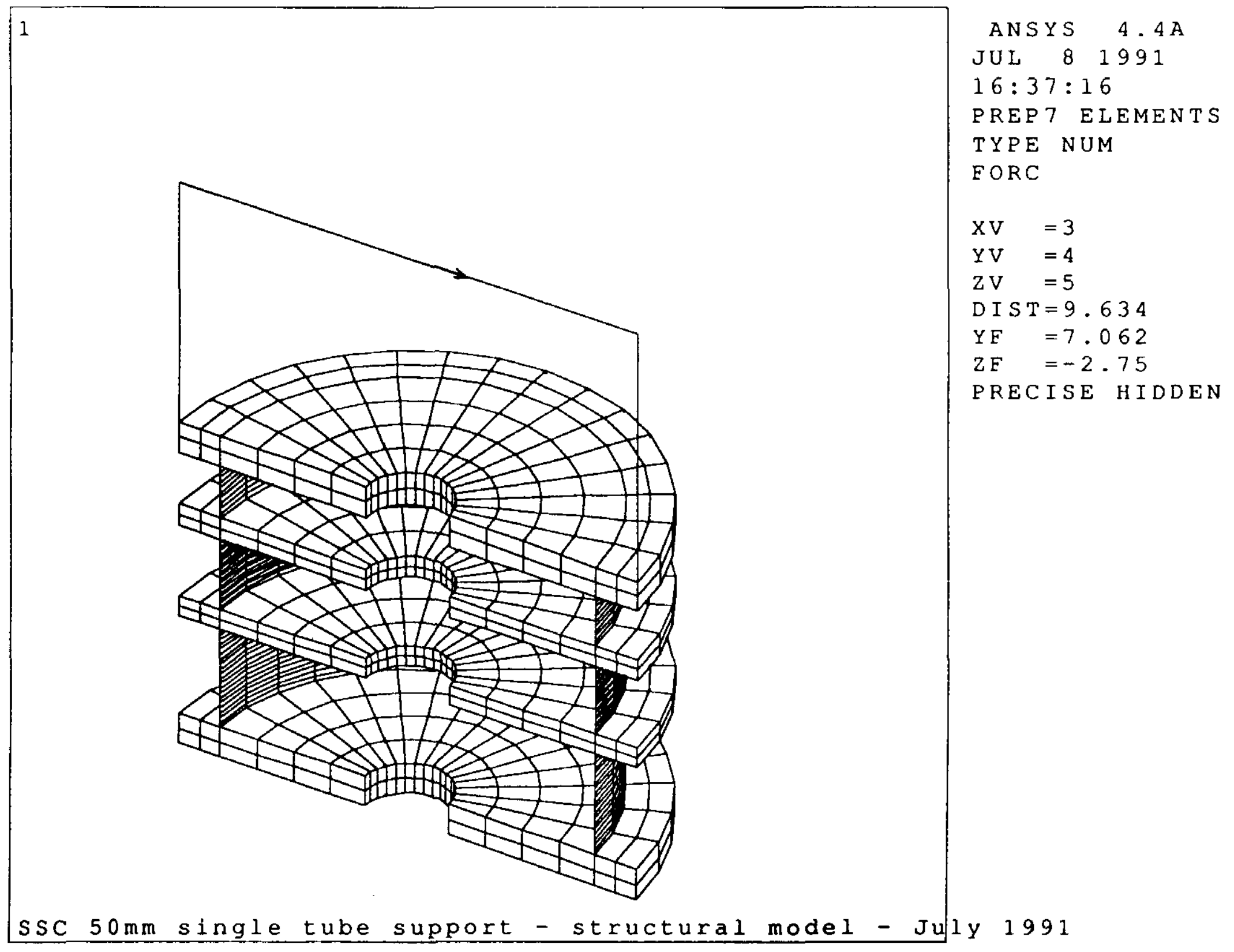


/PREP7

/TITLE,50mm single tube support - thermal model - July 1991

/NOPR

\section{$C * * *$}

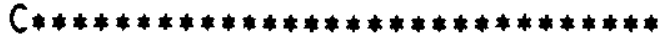

C*** T. Nicol - Fermilab ****

C*** July 1991 ****

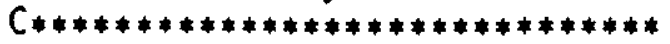

C****

C*** Filename: 50m_single_tube_thermal.026

$C * * *$

C*** This is a thermal model for an SSC style support post. I can accommodate

C*** different tube diameters, wall thicknesses, and materials for each tube

C*** section, i.e. $300 \mathrm{~K}$ to $80 \mathrm{~K}, 80 \mathrm{~K}$ to $20 \mathrm{~K}$, and $20 \mathrm{~K}$ to $4.5 \mathrm{~K}$. It also includes

$C * * *$ the effect of intercept strap and cold mass cradle thermal impedences.

$C * * *$

C*** Refer to log book 10 , pages 159-174 for model development ****

$C * * *$

/SHOW, $X 11$

NTBC , 1

$\mathrm{KAN},-1$

$E T, 1,32$ *2-d heat conducting bar...

C****

C*** Define variable parameters ****

$C * * *$

*SET, OD1, 9.0

*SET, OD2, 9.0

*SET, 0D3, 9.0

*SET, T1,0.110

*SET, T2, 0.090

*SET, T3, 0.080

*SET, L80, 2.500

*SET, L20, 1.750

*SET, L4 1.250

*SET, LCDL, 1.000

*SET, TFL, 0.75

*SET, TINT, 0.500

*SET, PI , 3.141593

- tube OD (300K to 80K) (in)...

- tube OD (80K to 80K) (in)...

* tube OD (20K to 4K) (in)...

* tube thickness (300K to 80K)...

* tube thickness (80K to 20K)...

* tube thickness (20K to $4 K$ )...

* 300K to 80K tube length (in)...

* 80K to $20 K$ tube length (in)...

* 20K to $4 K$ tube length (in)...

* cradle length (in)...

* top and bottom flange thicknesses (in)...

* intercept thicknesses (in)...

* pi...

*SET, ATB1 , $(P I *(0 D 1 * T 1-T 1 * T 1))$

*SET, ATB2, (PI* (OD2*T2-T2*T2))

* tube cross section ( $300 \mathrm{~K}$ to $80 \mathrm{~K}$ ) (in2)...

*SET, ATB3, (PI* (0D3*T3-T3*T3))

* tube cross section ( $80 K$ to $20 K$ ) (in2)...

*SET, ATB1, $($ ATB1*6.4516)

*SET, ATB2, (ATB2*6.4516)

$*$ SET, ATB3, (ATB3*6.4516)

*SET, AFL, 202.68

*SET, ALCR, 0.838

*SET, AL80, 0.1111

* tube cross section (300K to 80K) (in2)...

- tube cross section ( $300 K$ to $80 K$ ) (cm2)...

* tube cross section (80K to $20 \mathrm{~K})(\mathrm{cm} 2) \ldots$

- tube cross section (20K to 4K) (cm2)...

* flange cross sectional areas (cm2)...

* cradle A/L (cm) ...

*SET, AL20, 0.0444

* 80K strap $A / L(\mathrm{~cm}) \ldots$

* 20K strap A/L (cm)...

*SET, H1, TFL

* heights (in)...

*SET, $\mathrm{H} 2,(\mathrm{H} 1+\mathrm{L} 80)$

*SET, $\mathrm{H3}$, ( $\mathrm{H} 2+\mathrm{TINT})$

-SET, $\mathrm{H4},(\mathrm{H3}+\mathrm{L} 2 \mathrm{O})$

*SET, H5, ( H4+TINT)

*SET, H6, (H5+L4)

*SET, H7, (H6+TFL)

$* \mathrm{SET}, \mathrm{H8},(\mathrm{H7}+\mathrm{LCDL})$

$C * * *$

$C * *$ Define material properties

$\mathrm{C} * * *$

$C * * *$ 
$C * * *=K X X$ VS. TEMPERATURE FOR 304 STN STL (MAT 1) $=$

$C * * *=$ UNITS: $W / C M-K$

$=$

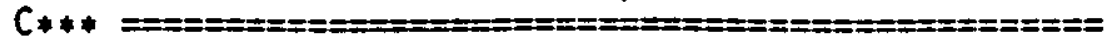

MPTEMP, , 4.0,6.0, 8.0, 10.0, 15.0, 20.0

MPTEMP, $30.0,40.0,50.0,60.0,70.0,80.0$

MPTEMP, , 100.0,120.0,140.0,160.0, 180.0,200.0

MPTENP, , 250.0,300.0

MPDATA, KXX, $1,, 0.0024,0.0039,0.0057,0.0077,0.0132,0.0195$

MPDATA, KXX, $1,0.0330,0.0470,0.0580,0.0680,0.0760,0.0830$

MPDATA, KXX, $1,0.0950,0.1030,0.1100,0.1200,0.1230,0.1300$

MPDATA, KXX, $1,0.1400,0.1500$

MPTEMP

\section{$C * * *$}

$C * * *===========$

$C * * *=K X X$ VS. TEMPERATURE FOR G-11 (WARP) (MAT 2) $=$

$C * * *=\quad$ UNITS: $W / C M-K=$

$C * * *===========================$

MPTEMP, $4.0,6.0,8.0,10.0,15.0,20.0$

NPTENP, $30.0,40.0,50.0,60.0,70.0,80.0$

MPTEMP, $, 100.0,120.0,140.0,160.0,180.0,200.0$

MPTEMP, , 240.0,300.0

MPDATA, KXX, $2,0.00072,0.00099,0.00120,0.00136,0.00163,0.00182$

MPDATA, KXX, $2,, 0.00211,0.00236,0.00260,0.00284,0.00308,0.00331$

MPDATA, KXX, $2,, 0.00378,0.00423,0.00466,0.00507,0.00546,0.00582$

MPDATA, KXX,2, $0.00649,0.00735$

MPTEMP

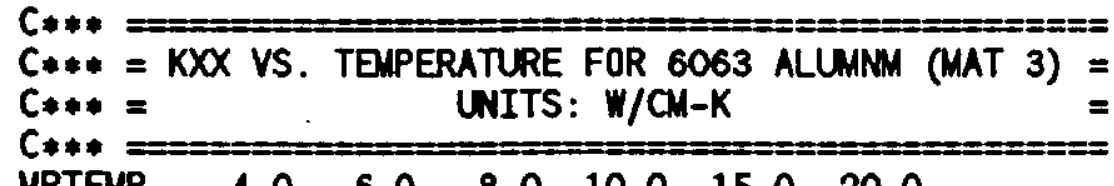

MPTEMP, $4.0,6.0,8.0,10.0,15.0,20.0$

MPTEMP, , 30.0, 40.0, 50.0, 60.0,70.0,80.0

MPTEMP, , $100.0,120.0,140.0,160.0,180.0,200.0$

MPTEMP, , 250.0, 300.0

MPDATA, KXX, 3, $0.3400,0.5100,0.6900,0.8600,1.3000,1.7000$

MPDATA, KXX,3, 2. $2.3000,2.7000,2.8000,2.7000,2.5000,2.3000$

MPDATA, $K X X, 3,2.1000,2.0500,2.0000,2.0000,2.0000,2.0000$

MPDATA, KXX, 3, 2.0000,2.0000

MPTEMP

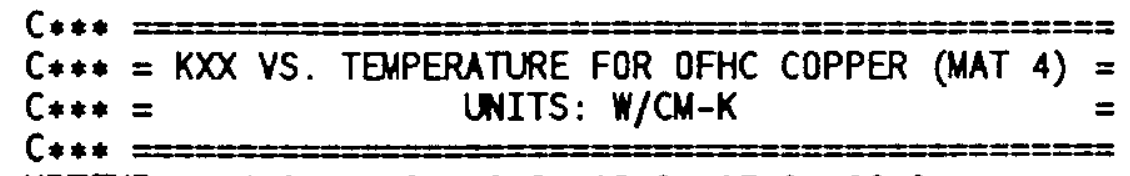

MPTEMP, $4.0,6.0,8.0,10.0,15.0,20.0$

MPTEMP, , 30.0, 40.0, 50.0, 60.0, 70.0, 80.0

MPTEMP, , $100.0,120.0,140.0,160.0,180.0,200.0$

MPTEMP, , 250.0,300.0

MPDATA, KXX, $4,2.4000,3.7000,4.7000,6.0000,8.5000,11.000$

MPDATA, $K X X, 4,, 12.000,10.000,7.7000,6.2000,5.5000,4.9000$

MPDATA, KXX,4, 4.5000,4.3000,4.2000,4.1000,4.0000,4.0000

MPDATA, KXX,4, $4.0000,4.0000$

MPTEMP

$C * * *==============$
$C * * *=K X X$ VS. TEMPERATURE FOR UNIAXIAL GRP (MAT 5) $=$
$C * * *=$
UNITS: W/CM-K
MPTEMP, $4.0,5.0,7.0,9.0,12.0,15.0$
MPTEMP, $20.0,25.0,30.0,60.0,80.0,100.0$

MPTEMP, , 150.0,200.0, 250.0,300.0

MPDATA, KXX , 5, $0.00052,0.00055,0.00060,0.00068,0.00070,0.00080$ 
MPOATA, KXX, 5, $0.00100,0.00120,0.00180,0.00400,0.00610,0.00820$

MPDATA , KXX, $5,0.01500,0.02000,0.02800,0.03200$

MPTEMP

$C * * *$

$C * * *$ Define real constants ****

$C * * *$

$R, 1, A F L$

- bottom flange...

$R, 2, A T B 1$

$R, 3, A F L$

$R, 4, A$ TB2

$R, 5, A F L$

$R, 6, A T B 3$

$R, 7, A F L$

$R, 8,(A L C R * 2.54)$

$R, 9,(A L 80 * 2.54)$

$R, 10,(A L 20 * 2.54)$

- 300K to $80 K$ composite tube...

* 80K intercept...

* 80K to 20K composite tube...

* 20K intercept...

* 20K to $4 K$ composite tube...

* top ring...

* cradle...

$C * * *$

$C * * *$ Define nodes

* 80K intercept strap...

* 20K intercept strap...

C***

CSYS, 0

$N, \quad 1,0.0,0.0$

$\mathrm{N}, \quad 5,0.0, \mathrm{H} 1$

$N, \quad 9,0.0, \mathrm{H}_{2}$

$N, 13,0.0, \mathrm{H3}$

$N, 17,0.0, \mathrm{H} 4$

$N, 21,0.0, \mathrm{H} 5$

$N, 25,0.0, \mathrm{H} 6$

$N, 29,0.0, \mathrm{H} 7$

$N, 33,0.0, \mathrm{H} 8$

FILL, 1,5

FILL, 5,9

FILL, 9,13

FILL $, 13,17$

FILL, 17, 21

FILL, 21, 25

FILL, 25, 29

FILL, 29, 33

NGEN, $2,90,11,, 0.0,0.0$ node 101 coincident with $11 \ldots$

NGEN, $2,87,19,, 0.0,0.0$ * node 106 coincident with $19 \ldots$

$\mathrm{N}, 105,1.0,(\mathrm{H} 2+\mathrm{H} 3) / 2.0$

$N, 110,1.0,(\mathrm{H} 4+\mathrm{H} 5) / 2.0$

FILL, 101, 105

FILL, 106, 110

$\mathrm{C} * * *$

$C * * *$ Convert inches to $\mathrm{cm} * * * *$

$C * * *$

NSCALE , $0, A L L, ~, 2.54,2.54$

$C * * *$

$C * * *$ Define elements

$C * * *$

TYPE, 1

$C * * *$

$C * * *$ Bottom flange ****

C****

MAT, 1

REAL, 1

$E, 1,2$

EGEN $4,1,-1$

$C * * *$

$C * * * 300 K$ to $80 K$ composite tube 
$C * * *$

MAT, 2

REAL, 2

$E, 5,6$

EGEN , 4, 1, -1

C****

C*** 8OK intercept ****

$C * * *$

MAT, 3

REAL, 3

$E, 9,10$

EGEN , 4, 1,-1

$C * *$

$C * * * 80 K$ to $20 K$ composite tube ****

$C * * *$

MAT, 2 * glass...

C*** MAT, 5 * graphite...

REAL, 4

$E, 13,14$

EGEN, $4,1,-1$

C***

C*** 20K intercept ****

C****

MAT, 3

REAL, 5

$E, 17,18$

EGEN , 4, 1,-1

C****

C*** 20K to $4 K$ composite tube ****

$C * * *$

C*** MAT, 2 * glass...

MAT, 5 * graphite...

REAL, 6

$E, 21,22$

EGEN, 4, 1,-1

$C * * *$

C*** Top flange ****

$C * * *$

MAT, 1

REAL, 7

$E, 25,26$

EGEN, $4,1,-1$

C***

C*** Cradle ****

$C * * *$

MAT, 1

REAL, 8

$E, 29,30$

EGEN, 4, 1, -1

$C * * *$

C*** 80K intercept strap ****

$C * * *$

MAT, 4

REAL, 9

E, 101,102

EGEN, 4, 1, -1

C***

C*** 20K intercept strap

$C * * *$

MAT, 4 
REAL, 10

$E, 106,107$

EGEN, 4, 1,-1

$C * * *$

$C * * *$ Merge coincident nodes and reorder wavefront

$C * * *$

MUMMRG, NODE, 0.01

WSORT, Y,O

$C * * *$

C*** Define temperature boundary conditions ****

$C * * *$

NT, 1, TEMP, 300.0

NT, 105, TEMP, 80.0

NT, 110, TEMP, 20.0

NT, 33, TEXP, 4.5

$C * * *$

C*** Define load step ****

$C * * *$

TUNIF, 300.0

$\mathrm{KBC}, 1$

CNVR, 0.1

KRF, 1

ITER, $-100,100,100$

/GOPR

AFURITE

FINISH

/INPUT, 27

FINISH 
1

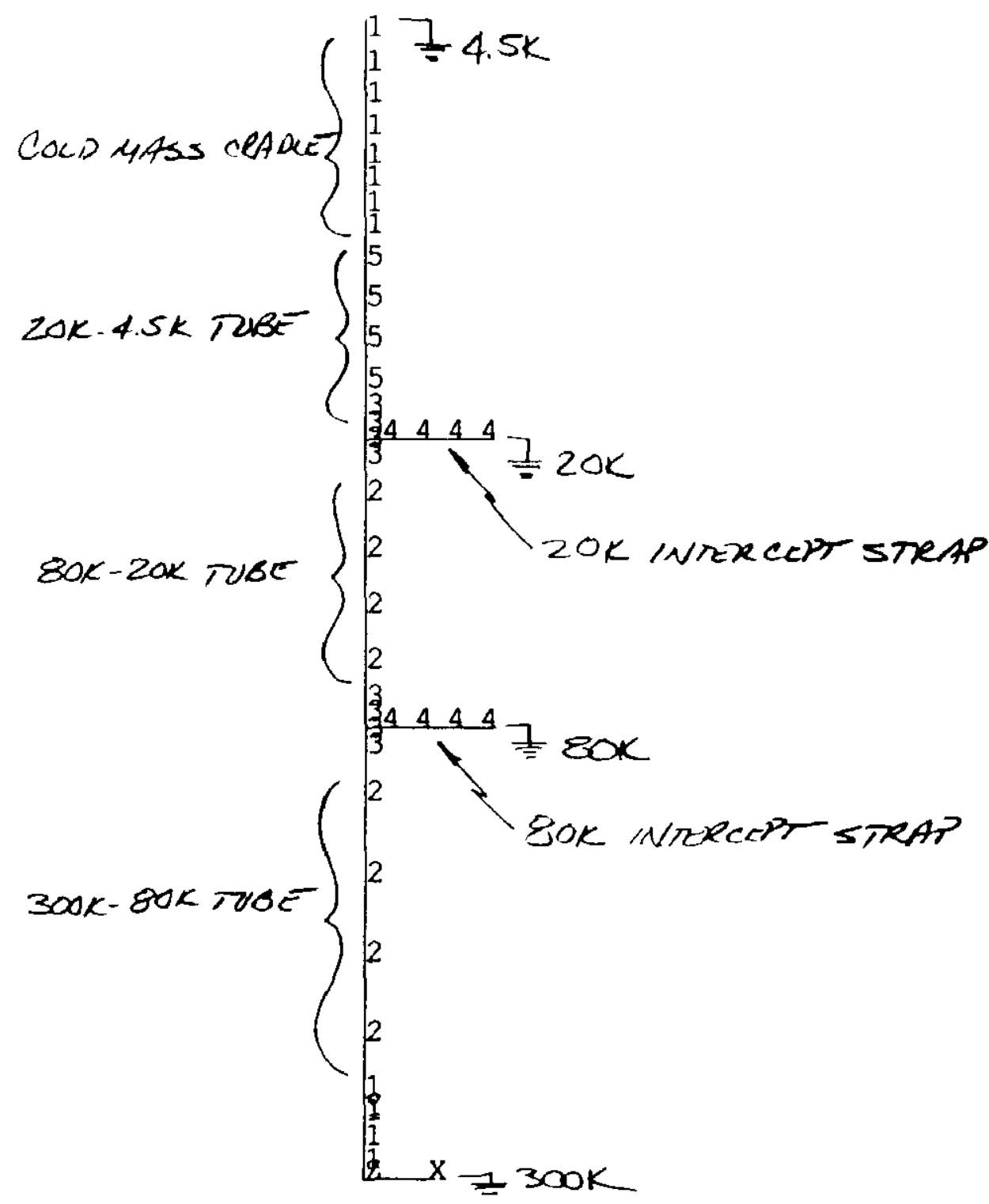

$$
\begin{aligned}
& \text { ANSIS } \quad \text { 4. } 4 \text { A } \\
& \text { JUL } 91991 \\
& 9: 15: 58 \\
& \text { PREP } 7 \text { ELEMENTS } \\
& \text { MAT NOM } \\
& \text { RV = } 1 \\
& \text { DIST }=12.573 \\
& \text { XE }=1.27 \\
& \text { YE }=11.43
\end{aligned}
$$

$50 \mathrm{~mm}$ single tube support - thermal model - July 1991 